\title{
Gradient HPLC in the determination of drug lipophilicity and acidity*
}

\author{
Roman Kaliszan ${ }^{\dagger}$, Piotr Haber, Tomasz Bączek, and Danuta Siluk \\ Department of Biopharmaceutics and Pharmacodynamics, Medical University of \\ Gdańsk, Gen. J. Hallera 107, 80-416 Gdańsk, Poland
}

\begin{abstract}
The linear-solvent strength (LSS) model of gradient elution in high-performance liquid chromatography (HPLC) has been demonstrated to provide parameters of lipophilicity and acidity of analytes. $\mathrm{p} K_{\mathrm{a}}$ and $\log k_{\mathrm{w}}$ values are determined in three gradient runs. The first two experiments use an aqueous buffered eluent with a wide-range organic modifier gradient at $\mathrm{pH}$ of buffer, providing suppression of ionization of the analyte. That experiment allows an estimate of contents of the organic modifier in the mobile phase (\%B), producing requested retention coefficient, $k$, for the nonionized form of the analyte. The next experiment is carried out with the latter $\% \mathrm{~B}$ and a $\mathrm{pH}$-gradient of the aqueous component of the eluent that is sufficient to overlap possible $\mathrm{p} K_{\mathrm{a}}$ value of the analyte. The initial $\mathrm{pH}$ of the buffer used to make the mobile phase is selected to insure that the analyte is in nonionized form. The resulting retention time allows an estimate of $\mathrm{p} K_{\mathrm{a}}$ in a solvent of the given $\% \mathrm{~B}$.

The $\log k_{\mathrm{w}}$ parameter obtained correlated well with the corresponding value obtained by the standard procedure of extrapolation of retention data determined in a series of isocratic measurements. The correlation between $\log k_{\mathrm{w}}$ and the reference parameter of lipophilicity, $\log P$, was very good for a series of test analytes. The values of $\mathrm{p} K_{\mathrm{a}}$ were found to correlate with the literature $\mathrm{p} K_{\mathrm{a}}$ data determined in water for a set of aniline derivatives studied.
\end{abstract}

\section{INTRODUCTION}

More than a century ago, Overton [1], Meyer [2], and Baum [3] reported relationships between affinity to lipids and biological (anesthetic) activity of chemical substances. Now, it is commonly acknowledged that lipophilicity or lipid/water partition properties affect most of the processes at the basis of drug action (Fig. 1). In the case of ionizable drugs, the process in the pharmacokinetic phase of drug action (absorption, distribution, and excretion) depend additionally on dissociation of the drug in aqueous compartments of a living system separated by lipid membranes (Fig. 2). Therefore, determining lipophilicity (hydrophobicity) parameters and ionization constants of drug candidates is necessary at the early stages of the drug development process. Modern, highly efficient synthesis procedures typically provide large numbers of target compounds, often as a multicomponent mixture. That requires procedures for determining lipophilicity parameters and $\mathrm{p} K_{\mathrm{a}}$ values that are rapid and can be used with very small samples. Especially suitable appear to be the procedures providing the data requested without prior isolation of an individual component of a mixture. Chromatography is unique with that respect, especially if combined with universal analyte detection and identification methods, like mass spectrometry.

\footnotetext{
*Plenary lecture presented at the Hungarian-German-Italian-Polish Joint Meeting on Medicinal Chemistry, Budapest, Hungary, 2-6 September 2001. Other presentations are published in this issue, pp. 1387-1509.

${ }^{\dagger}$ Corresponding author: Tel.: + 4858 349-32-60; Fax: + 4858 349-32-62; E-mail: romankal@amg.gda.pl
} 


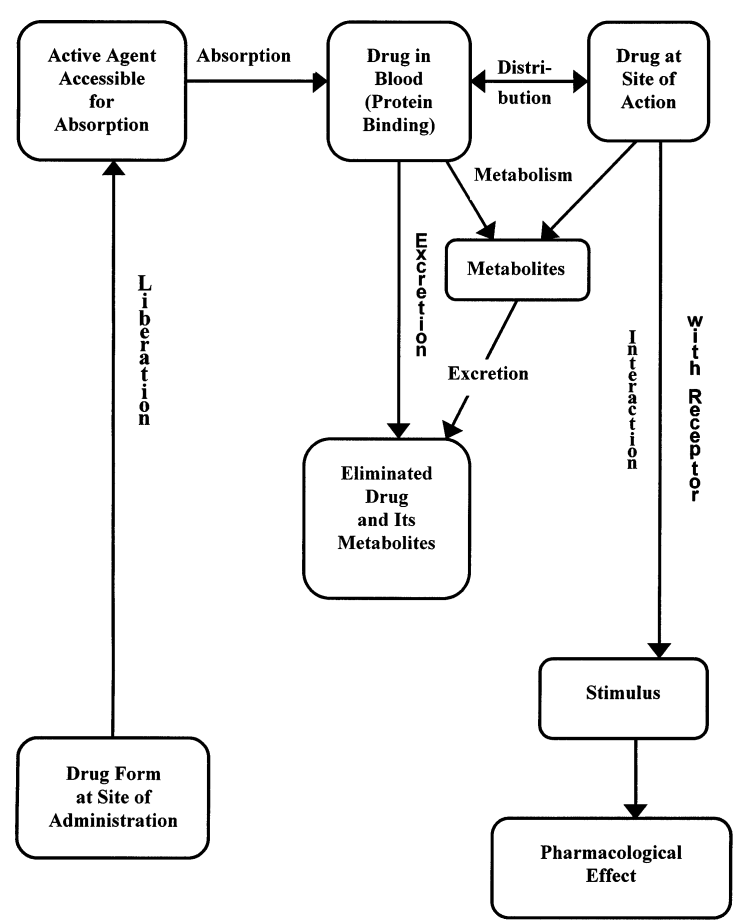

Fig. 1 Fundamental process at the basis of drug action.
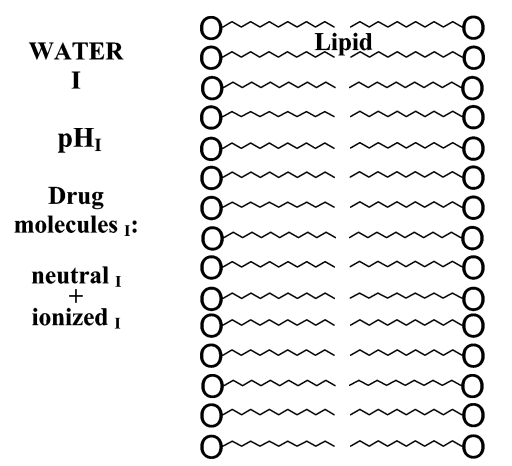
WATER
II
$\mathrm{pH}_{\text {II }}$
Drug
molecules $_{\text {II }}$ :
neutral ${ }_{\text {II }}$
$\stackrel{+}{\text { ionized }_{\text {II }}}$

Example:

Kanamycin: $\mathrm{pK}_{\mathrm{a}}=7.2$

Milk: $\mathrm{pH}_{\mathrm{I}}=6.4$

Blood: $\mathrm{pH}_{\mathrm{II}}=7.4$

$\frac{[\text { Drug in milk] }}{\text { [Drug in blood] }}=\frac{\left[1+10{ }^{\left.\mathbf{p} K_{\mathrm{a}}-\mathbf{p H}_{\text {milk }}\right]}\right.}{\left[1+10 K_{\mathrm{a}}-\mathbf{p H}_{\text {blood }}\right]} \approx 4.5$

Fig. 2 Ionizable drug in two aqueous systems separated by semipermeable lipid biomembrane.

The general methodology of determination of lipophilicity by reversed-phase liquid chromatography has been the subject of several reviews [4-12]. Usually, the lipophilicity parameters thus produced correlate well with the standard reference parameters of lipophilicity, i.e., the logarithms of 
$n$-octanol-water partition coefficient, $\log P$, introduced to medicinal chemistry by Hansch and Fujita [13]. For quantitative comparisons of relative lipophilicities of a series of drug analytes, the best suitable are the intercepts of the linear relationships between logarithm of retention coefficients $(\log k$ or $R_{M}$ ) and volume fraction of organic modifier in binary aqueous eluents. However, to get such normalized chromatographic parameters of lipophilicity $\left(\log k_{\mathrm{w}}, R_{M}{ }^{0}\right)$ is quite tedious because several (6-8) chromatographic runs are needed at a range of isocratic eluent compositions. Gradient HPLC can substantially speed up the procedure.

As most of the drugs are weak acids or bases, their distribution within body and overall activity depend on both lipophilicity and the degree of dissociation. For quite a number of established drugs the reference $\log P$ and $\mathrm{p} K_{\mathrm{a}}$ data have been compiled [14,15]. Similarly to $\log P$, there is a need to elaborate a fast and convenient procedure to evaluate also the $\mathrm{p} K_{\mathrm{a}}$ parameters of drug candidates.

The ionization of an acid can be represented by:

$\mathrm{HA} \Leftrightarrow \mathrm{H}^{+}+\mathrm{A}^{-}$

with the fraction of nondissociated molecules HA given by:

$$
f_{0}=1 /\left\{\left(K_{\mathrm{a}} / \mathrm{H}^{+}\right)+1\right\}
$$

If the fraction of dissociated molecules $\mathrm{A}^{-}$is $f_{-}$, and if the retention factor for non-dissociated and dissociated molecules is $k_{0}$ and $k_{-}$, respectively, the value of $k$ of partially dissociated analyte will be:

$$
k=f_{0} k_{0}+f_{-} k_{-}
$$

The study of retention factor, $k$, as a function of $\mathrm{pH}$ can be used to estimate a value of $\mathrm{p} K_{\mathrm{a}}$ for the compound in question.

In reversed-phase HPLC, the general equation relating retention coefficients, $k$, to volume percent of organic modifier in the binary aqueous mobile phase, $\Phi$, has a form:

$$
\log k=\log k_{\mathrm{w}}-S \Phi
$$

where $\log k_{\mathrm{w}}$ and $S$ are regression coefficients. Specifically, $\log k_{\mathrm{w}}$ is interpreted as hypothetical retention parameter corresponding to neat water (buffer) eluent.

Instead of extrapolating $\log k_{\mathrm{w}}$ from a series of 6-8 isocratic experiments of fixed $\Phi$, Snyder and Dolan [16] elaborated an approach allowing approximate evaluation of $\log k_{\mathrm{w}}$ from a single gradient run and its precise calculation from two gradient runs. Appropriate equation is:

$$
t_{R}=\left(t_{0} / b\right) \log \left(2.3 k_{0} b+1\right)+t_{0}+t_{D}
$$

where:

$$
b=V_{m} \Delta \Phi S /\left(t_{G} F\right)
$$

The symbols used in eqs. 5 and 6 mean: $t_{R}$ : analyte retention time $(\mathrm{min}) ; t_{0}$ : column dead time (min); $b$ : gradient steepness parameter; $k_{0}$ : value of $k$ corresponding to $0 \%$ of organic modifier in eluent; $t_{D}$ : gradient delay time, equal to $V_{D} / F ; V_{D}$ : equipment hold-up or "dwell" volume (ml); $\Delta \Phi$ : change in $\Phi$ during the gradient; $\Phi$ : volume fraction of strong solvent B in the mobile phase, equal to $\% \mathrm{~B} / 100 ; S$ : analyte parameter equal to $d(\log k) / d \Phi ; V_{m}$ : column dead volume (ml), equal to $t_{0} F ; t_{G}$ : gradient time $(\mathrm{min})$, i.e., time from beginning to end of gradient; $F$ : flow rate $(\mathrm{ml} / \mathrm{min})$.

Using eq. 5 and assuming typical value of $S=4$, one can estimate $\log k_{\mathrm{w}}$ from a single gradient run. Having $t_{R}$ data from two gradient runs of different $t_{G}$, one gets exact value of $\log k_{\mathrm{w}}$ by solving a set of two equations of the form of eq. 5 . That can be done automatically using chromatographic software such as DryLab (LC Resources, Walnut Creek, CA, USA) used in this work.

The estimation of $\mathrm{p} K_{\mathrm{a}}$ using either isocratic or gradient data typically requires several experiments to define the plot of $k$ vs. $\mathrm{pH}$. An alternative procedure proposed by Snyder and co-workers [17-19] is 
based on a single gradient run. It is assumed that a preceding gradient run(s) for the estimation of log $k_{\mathrm{w}}$ has already been carried out.

A typical plot of $\log k$ vs. mobile-phase $\mathrm{pH}$ (other conditions constant) for an acidic solute HA is shown in Fig. 3 (solid curve). The gradient begins at $\mathrm{pH}=\mathrm{pH}_{0}$, the retention of the nonionized form of the solute is $k_{0}$, and it is assumed that the retention of the ionized form of the solute can be approximated by $k_{i}=0$. The ionization of a single acidic group within the solute molecule is further assumed, at least for a $\mathrm{pH}$ range of $\left(\mathrm{p} K_{\mathrm{a}}-2\right)$ to $\left(\mathrm{p} K_{\mathrm{a}}+2\right)$. This plot of $\log k \mathrm{vs}$. $\mathrm{pH}$ can be approximated by an LSS relationship as shown by the dashed line of Fig. 3 [17]:

$$
\log k=\log k_{0}{ }^{\prime}-0.5\left(\mathrm{pH}-\mathrm{pH}_{0}\right)
$$

Equation 7 predicts values of $k$ with an error of less than $11 \%$ when the $\mathrm{pH}$ value is within \pm 0.4 units of $\mathrm{pH}=\mathrm{p} K_{\mathrm{a}}$. From eq. 7 and Fig. 3, for $\mathrm{pH}=\mathrm{p} K_{\mathrm{a}}$ and $k=k_{0} / 2$, it can be seen that:

$$
\log k_{0}{ }^{\prime}=\log \left(k_{0} / 2\right)+0.5\left[\left(\mathrm{p} K_{\mathrm{a}}\right)-\mathrm{pH}_{0}\right]
$$

If a linear $\mathrm{pH}$ gradient is assumed (other conditions constant), $\mathrm{pH}$ as a function of time, $t$, is given as:

$$
(\mathrm{pH})=\mathrm{pH}_{0}+\left(\Delta \mathrm{pH} / t_{G}\right) t
$$

Here, $\mathrm{pH}_{0}$ is the $\mathrm{pH}$ value at the start of the gradient, $\Delta \mathrm{pH}$ is the change in $\mathrm{pH}$ during the gradient, $t_{G}$ is the gradient time (during which $\mathrm{pH}$ changes), and $t$ is the time after the start of the gradient. Combining eqs. 7 and 9 yields:

$$
\log k=\log k_{0}{ }^{\prime}-0.5\left(\Delta \mathrm{pH} / t_{G}\right) t
$$

which is the form of an LSS gradient as described in by Snyder and Dolan [17]. Because:

$$
\log k=\log k_{0}-b\left(t / t_{0}\right)
$$

then from eqs. 10 and 11 one gets $b$ :

$$
b=0.5 t_{0} \Delta \mathrm{pH} / t_{G}=0.5 V_{m} \Delta \mathrm{pH} /\left(t_{G} F\right)
$$

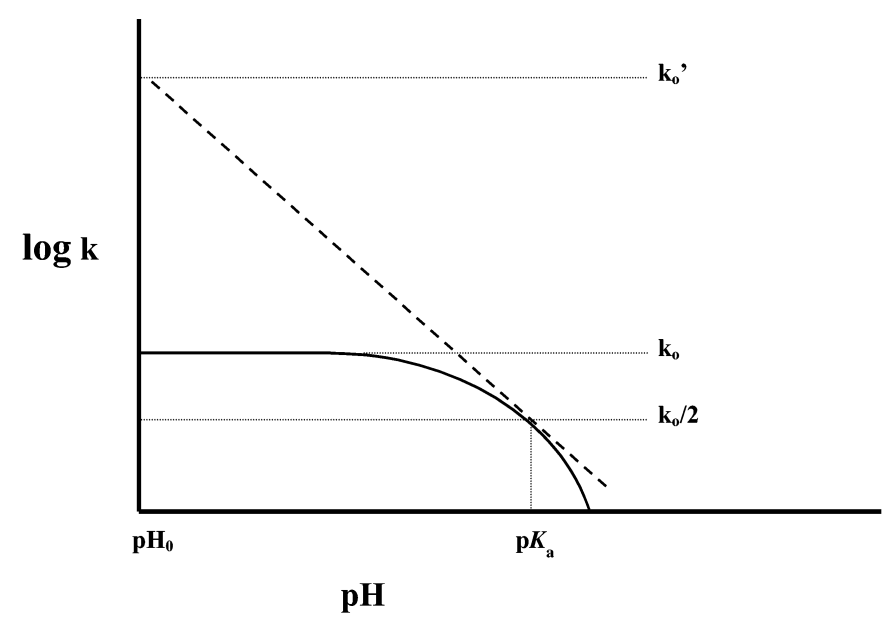

Fig. 3 Typical plot of $\log k$ vs. pH. Dotted line is an LSS theory based approximation. 
Denoting $\mathrm{pH}$ of the mobile phase at elution as $\mathrm{pH}^{* *}$, Snyder arrived eventually at the following equations allowing for calculation of $\mathrm{p} K_{\mathrm{a}}$ :

$$
\begin{aligned}
& \text { for acids: } \mathrm{p} K_{\mathrm{a}}=\mathrm{pH}^{* *}-2 \log \left(1.15 b k_{0}\right) \\
& \text { for bases: } \mathrm{p} K_{\mathrm{a}}=\mathrm{pH}^{* *}+2 \log \left(1.15 b k_{0}\right)
\end{aligned}
$$

The latter equation has been used in this work.

\section{EXPERIMENTAL}

\section{Equipment}

The HPLC system was an LC Module I Plus (Waters Associates, Milford, MA, USA) with a dwell volume of $4.3 \mathrm{ml}$, equipped with a pump, variable wavelength UV/VIS detector, autosampler, and thermostat. Data were collected using the Waters Millenium version 2.15 software and processed with DryLab program (LC Resources, Walnut Creek, CA, USA). $1 \% \mathrm{NaNO}_{3}$ was used as a dead time marker. Detection at $254 \mathrm{~nm}$ was a standard. The following columns were employed: Inertsil ODS-3, $150 \times 4.6 \mathrm{~mm}$ I.D., particle size $5 \mu \mathrm{m}$ (GL Sciences, Inc., Shinjuku-ku, Tokyo, Japan), XTerra RP 18 , $150 \times 4.6 \mathrm{~mm}$ I.D., particle size $5 \mu \mathrm{m}$ (Waters Corporation, Milford, MA, USA), both packed with octadecyl-bonded silica, Aluspher $100 \mathrm{RP}$-select B, $125 \times 4.0 \mathrm{~mm}$ I.D., particle size $5 \mu \mathrm{m}$ (Merck KGaA, Darmstadt, Germany) packed with polybutadiene-coated alumina and PRP-1, $150 \times 4.1 \mathrm{~mm}$ I.D., particle size $5 \mu \mathrm{m}$ (Hamilton Company, Reno, Nevada, USA), made of cross-linked polystyrene (divinylbenzene).

Mobile phases contained either methanol or aetonitrile as organic modifiers. Water or buffers of fixed $\mathrm{pH}$ formed the aqueous component of the eluent.

The injected sample volume was $20 \mu \mathrm{l}$. All of the chromatographic measurements were done at $35{ }^{\circ} \mathrm{C}$ with eluent flow rate of $1.5 \mathrm{ml} / \mathrm{min}$.

All of the reagents and analytes employed were of highest quality commercially available.

\section{Buffers}

Universal buffer [20] consisted of parts A and B. Part A was formed by three acids, all at concentration $0.004 \mathrm{M}$ : phosphoric, acetic, and boric. Part B, $0.02 \mathrm{M}$ sodium hydroxide, was added to part $\mathrm{A}$ at amounts required to get requested $\mathrm{pH}$. The $\mathrm{pH}$ of the buffers was measured at $21^{\circ} \mathrm{C}$ before mixing with organic modifiers. The measurements were done with an HI 9017 pH meter (Hanna Instruments, Bedfordshire, England).

\section{Determination of $\log \boldsymbol{k}_{\mathrm{w}}$ values by isocratic and gradient elution}

Two organic modifier gradients, 5-100\% B, at gradient times $t_{G}$, equal $20 \mathrm{~min}$ and $60 \mathrm{~min}$ were carried out. Based on retention times from two gradient runs with different $b$ value for each compound, $\log k_{\mathrm{w}}$ values were derived by the DryLab program. Based on eq. 4, DryLab software also predicted isocratic retention parameter, $k$, corresponding to a defined percent of given organic modifier.

A comparison of $\log k_{\mathrm{w}}$ values obtained by isocratic elution to those obtained by gradient elution was done for 37 analytes listed in Table 1. In gradient elution mode, the retention times derived from two gradient runs differing in gradient time served as input data and the $\log k_{\mathrm{w}}$ values were derived by the DryLab program. In the case of isocratic elution, the retention coefficients, $k$, were determined at fixed compositions of the binary organic solvent-water mobile phase ranging from 90:10 to 10:90 $(v / v)$. Methanol and acetonitrile were the organic solvents employed. Linear relationships were determined between $\log k$ and the volume percent of organic solvent in the eluent. On the basis of these relation- 


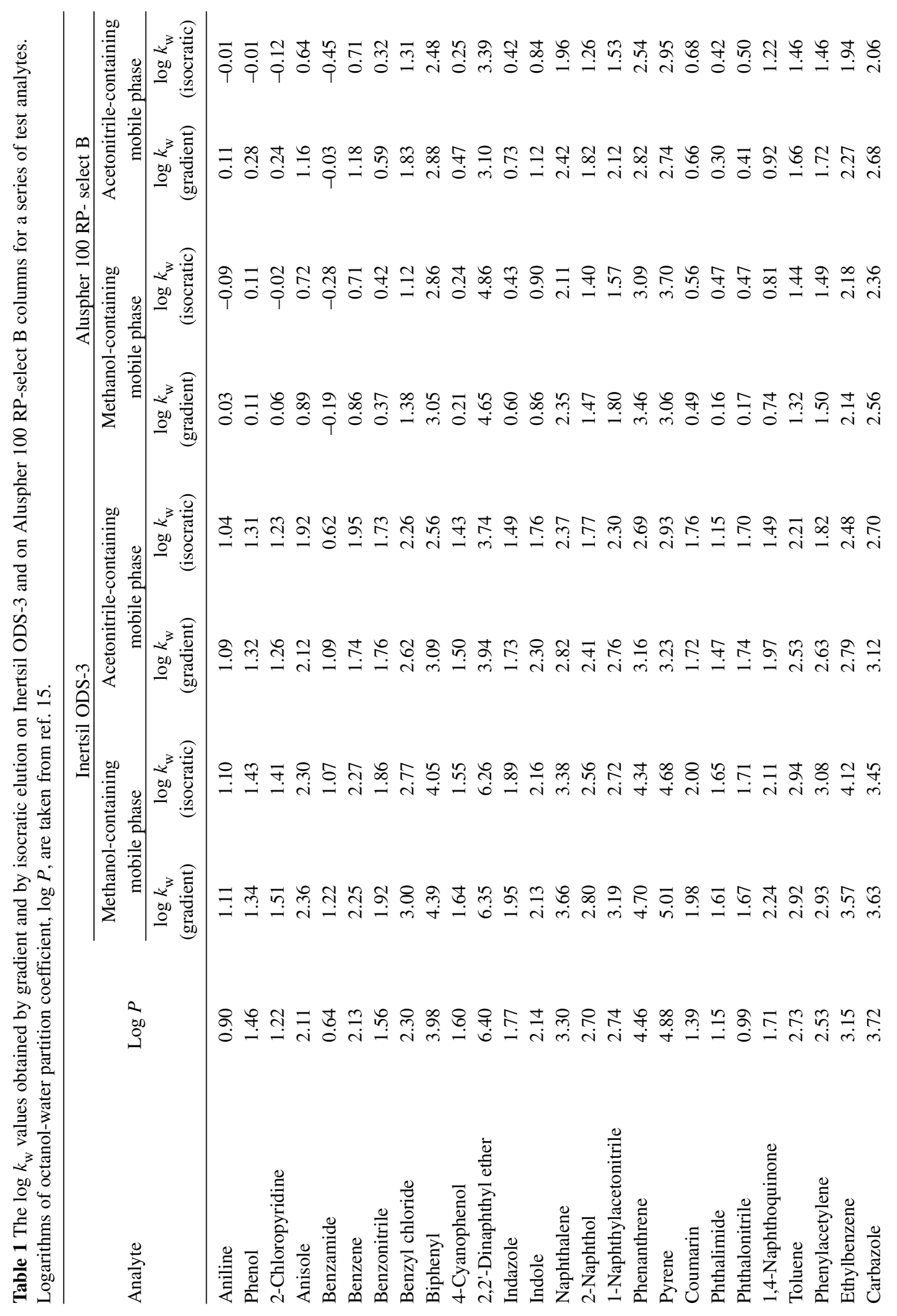




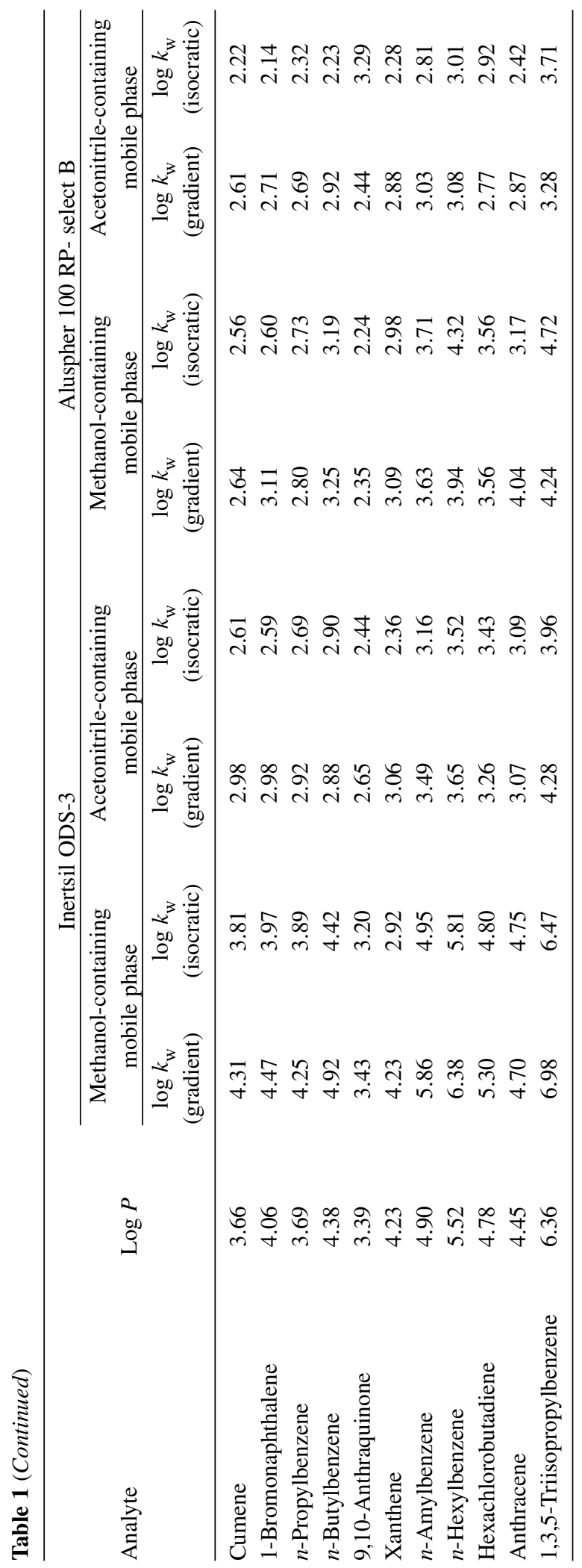

(C) 2001 IUPAC, Pure and Applied Chemistry 73, 1465-1475 
ships (in each case, the correlation coefficient was above 0.99), the values of $\log k_{\mathrm{w}}$ corresponding to $100 \%$ water were obtained by extrapolation. The $\log k_{\mathrm{w}}$ values obtained by isocratic and by gradient elution on Inertsil ODS-3 and on Aluspher 100 RP-select B columns are collected in Table 1 along with logarithms of octanol-water partition coefficients, $\log P$, taken from the literature [15].

\section{Determination of $\mathrm{p} K_{\mathrm{a}}$ values by gradient elution}

The $\mathrm{pH}$ gradient of the aqueous component of the mobile phase was programmed for the selected $k$ value of each compound. Percent of organic modifier was kept constant during chromatographic run, while composition of buffer components was linearly changed during a programmed gradient time. For the basic compounds studied, $\mathrm{pH}$ was 10.5 at the start and 3.0 at the end of gradient $(\Delta \mathrm{pH}=7.5)$.

\section{RESULTS AND DISCUSSION}

In Table $1, \log k_{\mathrm{w}}$ values are collected as determined by isocratic and by gradient method for structurally diversified analytes at $\mathrm{pH}$ conditions providing suppression of ionization. Apparently, the $\log k_{\mathrm{w}}$ values produced by the two methods are closely similar. That is the case for both columns (Inertsil ODS-3 and Aluspher 100 RP-select B) and the two organic modifiers (methanol, acetonitrile) studied. A higher correlation (Fig. 4) is observed for the methanol-containing mobile phases $(R>0.98)$. Nevertheless, the correlations found for the acetonitrile-containing mobile phases remain high $(R>0.95)$.
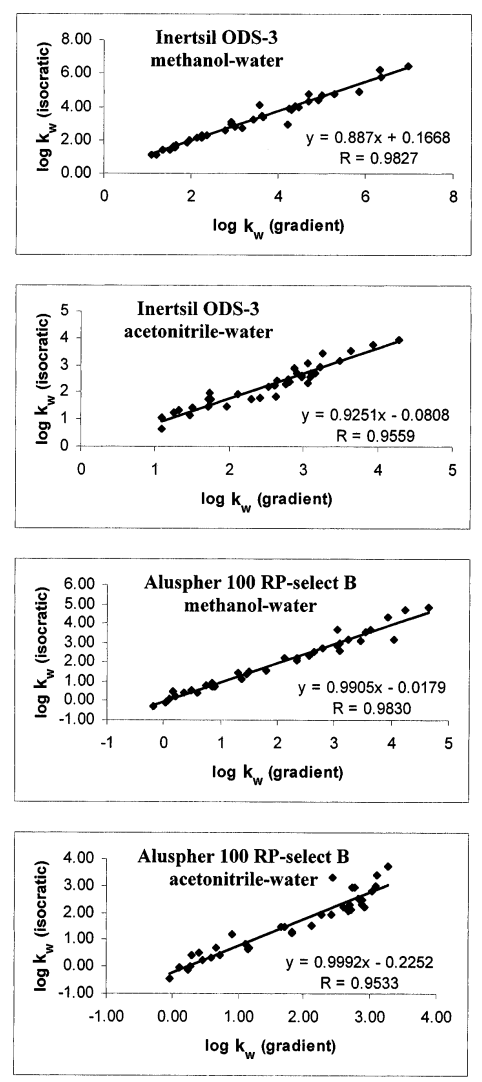

Fig. 4 Correlation between $\log k_{\mathrm{w}}$ determined by gradient vs. isocratic method for a series of analytes from Table 1. 
Figure 5 demonstrates that the chromatographic parameters of lipophilicity, $\log k_{\mathrm{w}}$, correlate very well with $\log P$ of analytes. The correlation is best for the alumina-based column and methanol as organic modifier. That observation once more confirms the unique suitability of alumina-based stationary phases for quantification of hydrophobicity, as was observed years ago [21].

The relationships derived by Snyder $[18,19]$ to determine $\mathrm{p} K_{\mathrm{a}}$ by gradient HPLC (eqs. 7-14) identify several factors affecting the final result. Apparent $\mathrm{p} K \mathrm{a}$ depends, among others, on the percent of organic modifier in the mobile phase, which $\mathrm{pH}$ is changed according to a program during elution. Such changes are difficult to predict, as illustrated in Fig. 6. Extrapolation of the relationship between apparent $\mathrm{p} K_{\mathrm{a}}{ }^{*}$ and the percent of organic modifier to the value corresponding to pure buffer does not produce the expected reference value of $\mathrm{p} K_{\mathrm{a}}$.

By the trial-and-error method, we arrived at experimental conditions providing $\mathrm{p} K_{\mathrm{a}}$ values for a series of aniline derivatives that are in accordance with the literature $\mathrm{p} K_{\mathrm{a}}$ data (Table 2). As evident from the table, each analyte requires different starting conditions for $\mathrm{pH}$ gradient. Having such conditions adjusted individually for 7 anilines, their $\mathrm{p} K_{\mathrm{a}}$ values could be determined. For five of them, the literature $\mathrm{p} K_{\mathrm{a}}$ values are available. The agreement is evident, although there are significant differences in absolute values, especially in the case of 2-chloroaniline.
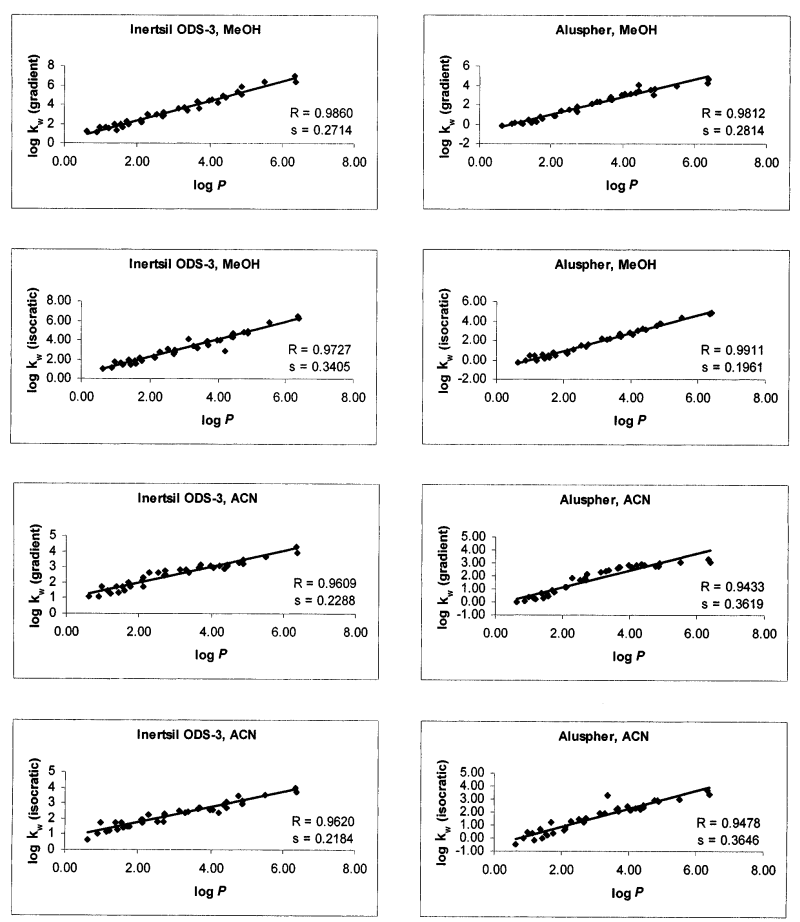

Fig. 5 Linear relationships $\log k_{\mathrm{w}}=k_{1}+k_{2} \log P$ between $\log k_{\mathrm{w}}$ data obtained by isocratic and gradient method and the logarithm of $n$-octanol/water partition coefficient, $\log P ; R$ is correlation coefficient, $s$ is standard error of estimate. 
Table 2 Conditions applied for determination of $\mathrm{p} K_{\mathrm{a}}$ of a series of anilines by gradient HPLC: Xterra column, $t_{G}$ of $\mathrm{pH}$ gradient, $\Delta \mathrm{pH}=7.50$, value of $b$ equal 1.15 .

\begin{tabular}{|c|c|c|c|c|c|c|c|c|c|c|}
\hline \multirow[b]{2}{*}{ Analyte } & \multirow[b]{2}{*}{$\begin{array}{c}\% \mathrm{~B} \\
(\mathrm{MeOH})\end{array}$} & \multicolumn{4}{|c|}{ pH gradient program } & \multirow[b]{2}{*}{$k_{0}$} & \multirow[b]{2}{*}{$t_{R}$} & \multirow[b]{2}{*}{$\mathrm{pH}^{* *}$} & \multirow[b]{2}{*}{$\underset{\text { (grad.) }}{\mathrm{p} K_{\mathrm{a}}}$} & \multirow[b]{2}{*}{$\begin{array}{l}\mathrm{p} K_{\mathrm{a}} \\
\text { (lit.) }\end{array}$} \\
\hline & & $\begin{array}{c}\% \mathrm{~A} \\
\text { (acids) } \\
\mathrm{pH}=\end{array}$ & $\begin{array}{c}\% \mathrm{C} \\
(\mathrm{NaOH})\end{array}$ & $\begin{array}{c}\% \mathrm{~A} \\
\text { (acids) }\end{array}$ & $\begin{array}{c}\% \mathrm{C} \\
(\mathrm{NaOH}) \\
3.00\end{array}$ & & & & & \\
\hline 3-Methylaniline & 9 & 48.1 & 42.9 & 78.9 & 12.1 & 8.10 & 7.92 & 2.71 & 4.77 & 4.71 \\
\hline 4-Chloroaniline & 26 & 39.1 & 34.9 & 64.2 & 9.8 & 7.94 & 8.23 & 2.09 & 4.13 & 3.98 \\
\hline 2-Chloroaniline & 26 & 39.1 & 34.9 & 64.2 & 9.8 & 8.06 & 8.68 & 1.19 & 3.25 & 2.66 \\
\hline 3-Chloroaniline & 27 & 38.6 & 34.4 & 63.3 & 9.7 & 8.11 & 8.49 & 1.56 & 3.62 & 3.52 \\
\hline$N$-Ethylaniline & 32 & 36.0 & 32.0 & 59.0 & 9.0 & 8.06 & 7.90 & 2.74 & 4.80 & 5.12 \\
\hline 3,4-Dichloroaniline & 45 & 29.1 & 25.9 & 47.7 & 7.3 & 7.94 & 8.08 & 2.39 & 4.43 & 2.97 \\
\hline 3,5-Dichloroaniline & 50 & 26.4 & 23.6 & 43.4 & 6.6 & 8.23 & 8.34 & 1.86 & 3.93 & 2.51 \\
\hline
\end{tabular}
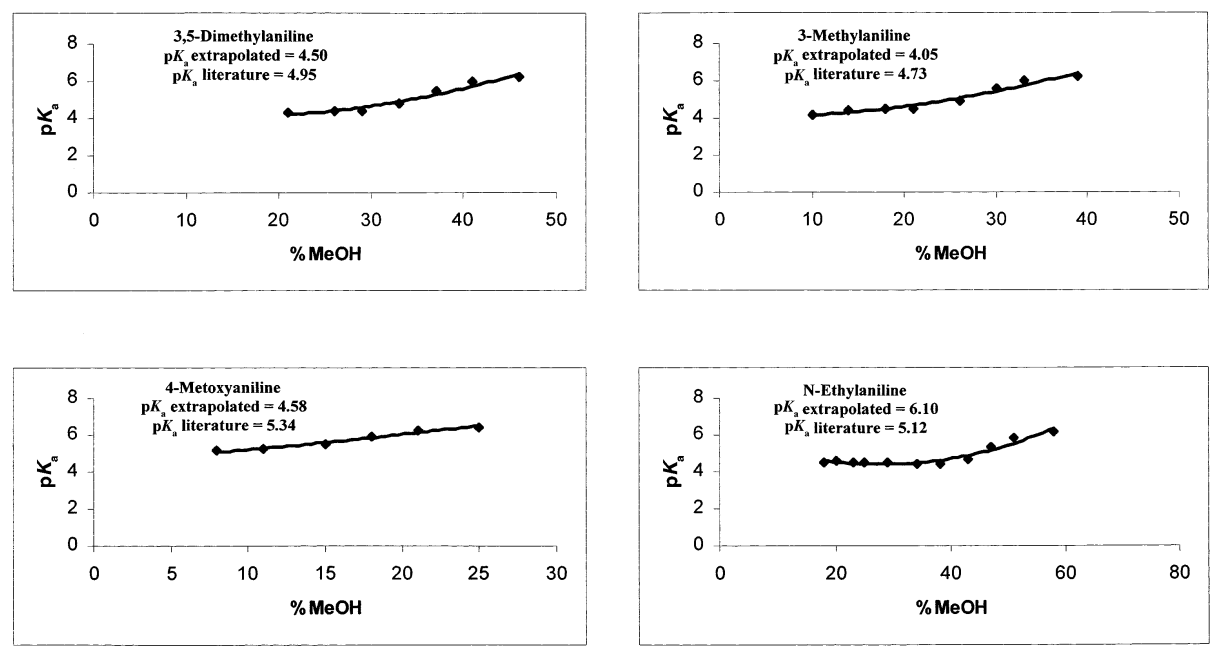

Fig. 6 Relationship between apparent $\mathrm{p} K_{\mathrm{a}}$ and percent of organic modifier in mobile phase: column PRP-1, citrate buffer, starting $\mathrm{pH}=6.50, \Delta \mathrm{pH}=3.50, t_{G}$ of $\mathrm{pH}$ gradient $5.00 \mathrm{~min}$.

\section{CONCLUSIONS}

In conclusion, the following can be stated:

- Gradient HPLC is a fast and convenient method of efficient screening of lipophilicity of drug candidates.

- $\quad$ Two gradient runs suffice to get a reliable parameter of analyte lipophilicity.

- $\quad$ Estimates of $\mathrm{p} K_{\mathrm{a}}$ can be obtained from three gradient runs: two with modifier gradient and the next with $\mathrm{pH}$ gradient of the eluent buffer at the conditions adjusted to individual analytes. 


\section{REFERENCES}

1. E. Overton. Z. Physikal. Chem. 22, 189 (1897).

2. H. Meyer. Arch. Exp. Pathol. Pharmakol. 42, 109 (1899).

3. F. Baum. Arch. Exp. Pathol. Pharmakol. 42, 119 (1899).

4. P. W Carr. Microchem. J. 48, 4 (1993).

5. R. Kaliszan. J. Chromatogr. A 656, 417 (1993).

6. W. J. Lambert. J. Chromatogr. A 656, 469 (1993).

7. J. G. Dorsey and M. G. Khaledi. J. Chromatogr. A 656, 485 (1993).

8. K. Valko, L. R. Snyder, J. L. Glajch. J. Chromatogr. A 656, 501 (1993).

9. L. C. Tan and P. W. Carr. J. Chromatogr. A 656, 521 (1993).

10. H. van de Waterbeemd, M. Kansy, B. Wagner, H. Fischer. In Lipophilicity in Drug Action and Toxicology, V. Pliska, B. Testa, H. van de Waterbeemd (Eds.), p. 73, VCH, Weinheim (1996).

11. R. Kaliszan. Structure and Retention in Chromatography: A Chemometric Approach, Harwood Academic, Amsterdam (1997).

12. R. Kaliszan. J. Chromatogr. B 717, 125 (1998).

13. C. Hansch and T. Fujita. J. Am. Chem. Soc. 86, 1616 (1964).

14. P. N. Craig. In Comprehensive Medicinal Chemistry, Vol. 6, C. Hansch, P. G. Sammes, J. B. Taylor (Eds.), Pergamon Press, Oxford (1990).

15. C. Hansch, A. Leo, D. Hoekman. In Exploring QSAR: Hydrophobic, Electronic, and Steric Constants, S. R. Heller (Ed.), American Chemical Society, Washington, DC (1995).

16. L. R. Snyder and J. W. Dolan. J. Chromatogr. A 721, 3 (1996).

17. L. R. Snyder and J. W. Dolan. Adv. Chromatogr. 38, 115 (1998).

18. L. R. Snyder. Personal communication (1999).

19. R. Kaliszan, P. Haber, L. R. Snyder. "Estimation of compounds $p K_{a}$ and $\log k_{\mathrm{w}}$ values by means of two reversed-phase HPLC runs" in Book of Abstracts, $23^{\text {rd }}$ International Symposium on High Performance Liquid Phase Separations and Related Techniques HPLC'99, Granada, Spain, L/043.

20. I. Gajewska (Ed.). Polarografia. Poradnik fizykochemiczny. Wydawnictwo Naukowo-Techniczne, Warszawa (1974).

21. R. Kaliszan, R. W. Blain, R. A. Hartwick. Chromatographia 25, 5 (1988).

22. C. Hansch, P. G. Sammes, J. B. Taylor. In Comprehensive Medicinal Chemistry. The Rational Design, Mechanistic Study \& Therapeutic Application of Chemical Compounds, C. J. Drayton (Ed.), Vol. 6, Cumulative Subject Index \& Drug Compendium, Pergamon Press (1990). 